\title{
Sintesis normativa de la Ley del Suelo
}

\section{Hacia una justificación del Urbanismo}

En recuerdo de D. Gabriel del Valle, Abogado del Estado y querido compañero de claustro en el Instituto de Estudios de Administración Local.

\section{CONCEPTo}

Accediendo a amables indicaciones, que en nada sirven de atenuante o justificación a lo que pudiera tener de precipitado y somero este estudio, vamos a intentar hacer, como ya se ha llevado a cabo anteriormente en esta Revista (1), un esquema o sinopsis del articulado de la reciente Ley del Suelo y de la Ordenación Urbana.

Ante todo, habría que precisar el concepto general de esta importante, extensa y trascendental (2) disposición, no sólo desde el punto de vista estrictamente terminológico, sino más bien ontológico o gnoseológico. La nomenclatura legislativa ya sabemos que a veces es puramente convencional. Sin referirnos a los excesos anglo. sajones de denominación más o menos anecdótica, que llega en Estados Unidos a utilizar o vulgarizar los patronímicos de los autores o promotores de la ley, es evidente que el nombre dado a muchas leyes

(1) Ver, por ejemplo, la síntesis del sistema fiscal local que hizo ANtonio Hernández Carrillo cuando se promulgó el Decreto de Ordenación provisional de 25 de enero de 1946.

(2) Luego intentaremos demostrar por qué de la aplicación de estoo tres adjetivos tan calificativos. 
españolas no responde a la realidad (al menos de jure condendo), pues no describen, ni menos evocan, el contenido efectivo de sus preceptos. Ni siquiera los epítetos, que en son de burla inventa el vulgo, nos son de utilidad a este respecto. Si a una importantísima disposición se la llama Ley de enredamientos urbanos, a ésta se la dió el apodo de Ley del desconsuelo, y también el de Ley de ordeñación urbana. El problema se complica cuando, como en este caso, el nombre de la disposición ha de ser plural o mixto. Entonces el afán de abreviar amputa uno de los términos y la denominación resulta aún más inexacta. Nosotros, siguiendo esa inevitable tendencia, hemos incurrido en semejante falta, y quisimos remediarla, en lo posible, mediante el empleo de un subtítulo algo pretencioso y al parecer algo pedante, pero que creemos suficientemente ilustrativo para señalar una tendencia, así como para indicar en una gran parte el contenido de la Ley. No queremos ciertamente sugerir que ésta pretenda llevar, al campo del Derecho, material no apto para ser legislado, ni tampoco que entrañe una normación ex novo sin precedente alguno. El doble juego del título y subtítulo, completado o complementado con esta sencilla explicación preliminar (3), nos sirve para llamar la atención sobre el dualismo legislativo que la Ley de 12 de mayo de 1956 encierra en su misma unidad orgánica.

En efecto, dentro del ordenamiento que la referida Ley contiene, pueden distinguirse, entre otras muchas cosas (4), dos materias perfectamente delimitables desde un punto de vista objetivo, si

(3) Insistimos en su sencillez y casi laconismo. Deliberadamente no se ha querido recoger, ni aun en esquema dialéctico, todo el rico contenido doctrinal que se expone en su extensísimo preámbulo, así como en los discursos de presentación a las Cortes por el Ministro de la Gobernación y Director General de Administración Local. En aquella parte expositiva, como en esta interpretación auténtica de la doctrina que la nueva norma inspiró y en otros datos que contienen los documentados discursos de los Sres. Pérez González y García Hernández, puede hallar el lector explicaciones harto más convincentes sobre los objetivos o propósitos de la Ley, que superan la exégesis genérica que nosotros en este momento pudiéramos aducir.

(4) Muchas de orden substantivo y aun otras de organización administrativa (principio de cooperación, idem de especializacion presupuestaria, gerencia, nueva modalidad de tutela administrativa, etc.). 
bien en su normación aparezcan como inescindibles. De una parte podríamos distinguir, tanto por su número y extensión como por su rango normativo, un enorme porcentaje de artículos que tratan del régimen jurídico del suelo, y de otra, un porcentaje todavía mayor que se refiere más concretamente a la legalización del urbanismo.

Ahora bien, este planteamiento dicotómico, que incluso podría apoyarse topológicamente, relatando la ubicación o emplazamiento de cada materia dentro de la Ley, mediante cita de sus pertinentes artículos, es más especulativo que real. Técnicamente, esto es, a efectos de su aplicabilidad, las nuevas normas sobre el suelo no tendrian vigencia si no se encaminan a una finalidad urbanistica y a su vez las normas de ordenación de ciudades resultarían inaplicables sin el apoyo de las primeras. Es decir, que ambas se cierran como un todo indivisible si pretendiéramos tratarlas separadamente.

Queremos con esto resaltar que la Ley es algo más que simple amalgama o mera yuxtaposición de dos ordenamientos separables; que si bien en esencia y desde el punto de vista material, contiene dos normativas, técnicamente son complementarios, sin que puedan calificarse en sí de mutuamente subsidiarios. Ni el régimen jurídico del suelo puede reducirse a puro medio instrumental de la ordenación urbana, ya que afecta vital y existencialmente a una institución jurídica tan destacada como es el derecho de propiedad, ni meros án la ordenación urbanística puede colocársela en un lugar subalterno y accesorio de la propiedad inmobiliaria, que pretendiera a su vez servirse de ella de simple medio, como en algunas ocasiones ocurriera, para el agio, dentro de un amercado imperfecton (5) de terrenos urbanizados o urbanizables.

\section{a) ¿Reordenacion jurídica total o parcial del suelo?}

El legislador parece indicar su prioridad en el rótulo mismo de la Ley. Pero quizá lo ha hecho por razones de estilo, ya que desde el artículo $1 .^{\circ}$ hasta el 228 , Gltimo de aquélla, se ocupa pre-

(5) La expresión es del preámbulo. 
ferentemente de la ordenación urbana. Mas esta preferencia no relega a segundo plano el ordenamiento del dominio y demás derechos reales sobre el suelo y las fincas. Puede incluso decirse, sin énfasis alguno, que después de la Ley Hipotecaria (y en algunos destellos incluso antes que ella), la Ley que estudiamos es el complemento normativo más importante del Código civil para la ordenación de ciertos bienes inmuebles. No es, como podrá apreciar quien profundice en el alcance de sus preceptos, finicamente una ordenación urbanística; es también una ordenación parcial del Derecho inmobiliario. Si sus normas perduran o logran cierto nivel de vigencia, día llegará que los hipotecaristas investigarán el entramado de aquélla, como lo hicieron antes y después de 1909 con las sucesivas leyes hipotecarias, o como otros especialistas estudiaron las leyes de aguas o las de expropiación forzosa.

Ahora bien, nótese que hemos calificado a la Ley, respondiendo así al dilemático interrogante de este epígrafe, que es una ordenación parcial y que sólo afecta a ciertos bienes inmuebles. No constituye, pues, la nueva normación, una reforma completa y absoluta de los preceptos del Código civil relativos al dominio y demás derechos reales sobre bienes inmuebles situados en espacios urbanos o semiurbanos. De los rústicos (aun afectados en esa nueva área a que alude el artículo 64 como reserva urbana), poco o rada se dice.

En este sentido, la denominación de la Ley puede resultar excesiva, ya que una gran parte del régimen jurídico del suelo no se aborda, si bien en general se apuntan atisbos para el futuro y también una programática funcional para venideras reformas de nuestro primer gran Cuerpo legal. A este respecto, y también un poco ortopédicamente, puede afirmarse que la Ley de 12 de mayo de 1956 complementa el Código civil casi como el ordenamiento de aguas e hipotecario, si bien comparativamente con aquéllas, no podría conceptualmente encuadrarse el nuevo régimen de la propiedad urbana en la categoría de las propiedades especiales. Los dueños de terrenos o edificios afectados por ordenaciones urbanísticas no puede decirse que son titulares de una propiedad especial; el régimen jurídico de las aguas, como en diferente grado el de los montes, minas, obras intelectuales, patentes, etc., es mucho más 
especial que el régimen jurídico del suelo que la nueva Ley aporta.

Mas no se crea que ésta respeta inconmoviblemente un derecho quiritario, sino todo lo contrario, responde a las modernas tendencias que sociológica e ideológicamente se designan como función social de la propiedad y que económicamente propugnan una intensa movilización de los bienes inmuebles.

Si el hipotecarista o jurista especializado en problemas de propiedad inmueble tiene en la nueva Ley un horizonte constelado de promeșas y preocupaciones, el sociólogo podrá ver en la misma una instrumentación de esa idea madre de la moderna Política social que se conoce con el nombre de función social de la propiedad. Los principios sentados en el Fuero del Trabajo, primero, y en el Fuero de los Españoles, después, que a este respecto ya tuvieran su antecedente en el artículo 44 de la Constitución de 1931, reflejados asimismo en la parte dogmática del modernó Derecho constitucional comparado, encuentra en la Ley del Suelo más que un intento de desarrollo. También los moralistas o teólogos podrán ver reflejados en los principios que sus normas inspiran algunas doctrinas que van desde las Encíclicas de León XIII a los Mensajes de Pío XII.

\section{b) ¿Iuridificación del urbanismo?}

Ya en nuestra aIntroducción a una recopilación legislativa en materia de urbanismo.(6), publicada por el Instituto editor de esta Revista, insinuábamos los impactos que la legislación en dicha materia había producido sobre el Derecho administrativo general. Sin insistir en aquellos puntos de vista (muchos de los cuales habría sido oportuno tenerlos en cuenta como premisas previas, y sin profundizar siquiera en la evolución posterior del Derecho español, cabría formular un juicio a priori afirmativo.

El fundamento de esta afirmación podría buscarse con un trazado logístico de la curva que describe el ordenamiento inicialmente rudimentario del urbanismo español. Históricamente (ante todo, $\in \mathfrak{n}$ la "pequeña historia» jurídico-urbanística de nuestro siglo) se

(6) Derecho urbanistico español. 
advierte una evolución, que es casi mutación per saltum entre nuestras viejas leyes de ensanche y las modernas de ordenación urbana, pasando por el Reglamento de Obras del Estatuto municipal, la Ley de Carreteras, etc. Sería conveniente también imaginar, con más o menos racionalidad, aunque sí con cierto sistema, el modo y manera cómo algunas tendencias intervencionistas, planificadoras o simples modalidades en formas de vida o servicios, pueden trascender en la legislación. Mas, en último término, y prescindiendo de otros muchos argumentos, bastaría pensar en los efectos normativos de esta Ley misma para justificar filosófica, sociológica y legalmente, desde una base positiva y positivista, indiscutible respuesta afirmativa a aquel interrogante.

En efecto, la Ley que examinamos ofrece de por sí motivos bastantes para sostener que muchas doctrinas políticas, no pocas creencias o tendencias sociales y bastantes directrices técnicas (demográficas, arquitectónicas, ingenieriles, etc.) acerca del intervencionismo y la planificación en el desarrollo de ciudades, han adquirido sentido jurídico. Pero es más, se llevan y encierran dentro del campo del Derecho toda la serie de instrumentaciones administrativas, financieras y aun aquellas técnicas, las cuales no se aplican con exclusividad a los desenvolvimientos de la gran ciudad, al del supermunicipio o al cultivo de eso que llamaríamos, más que supermetrópolis, metápolis (7).

La civitas de tipo medio, e incluso la pequeña comunidad urbana diseminada, así como los núcleos rurales más o menos compactos, se someten a la vigencia de la Ley. Además, no sólo los actos del Estado, Provincia, Municipio y otros organismos públicos más - menos autónomos, sino que la misma acción de los particulares aislados o agrupados se institucionalizan jurídicamente; la acción espontánea o reflexiva de individuos, grupos o corporaciones se juridifica. La iniciativa privada se regula, la discrecionalidad, impa:sos o inercias de la Administración se dosifican y casi se codifican. Porque la Ley es un pequeño Código, no por el número de preceptos y el acentuado sistema de vertebración, sino por la tendew.

(7) Es casi la zona o comarca, superando la idea occidental y tradictonal de la polis griega. 
cia de reflejar en el campo forense todo un nuevo horizonte de actividades dentro de un cierto orden, método o sistema. Unas veces el orden estético se quiere acompañar de cierto cuño legal, así las garantías jurídicas para la protección del ornato, simetría en edificaciones, unidad arquitectónica, integridad del paisaje (artículos 15, 60 y siguientes) ; otras, el éticoeconómico para evitar especulaciones (arts. 86 a 101 sobre valoraciones), pretendiendo casi incrustar ex lege nuevas y variadas teorías sobre el valor; otras, el político-social, en las medidas legales, que, por ejemplo, representan la lucha contra el suburbio (art. 18), y la posibilidad de racionalizar las expansiones en las grandes concentraciones demográficas (8), tal como se perfila en ciertos párrafos de los artículos $2 .^{\circ}$ y $3 .^{\circ}$, así como en los $7 .^{\circ}$ a 10 y concordantes.

Muchos principios doctrinales del urbanismo se metamorfosearon en reglas de obligatoria observancia; la crisálida no llegará sin embargo a mariposa, pues ésta perdió sus alas para enredarse en un aparato administrativo, con sus inspecciones, recursos gubernativos, judiciales, etc. El mecanismo de la responsabilidad de funcionarios, concesionarios y empresarios (arts. 213 a 215) trata de dar forzosa consistencia a las voluntades que puedan promover 0 entorpecer la acción urbanística; de igual forma que el libre albe. drío de los constructores se somete a un tempus más o menos rígido, regido por plazos más o menos flexibles (arts. 112, 142 y concordantes).

Hasta los hechos físicos o situaciones materiales, como es, por ejemplo, el concepto legal de finca ruinosa, trata de aprehenderlo o aprisionarlo el legislador dentro de sus mandamientos (art. 170).

\section{Trascendencia de la nueva Ley}

Prometimos antes explicar el por qué la habíamos aplicado un triple apelativo: uno era de orden cuantitativo y trataba de ence-

(8) El dirigismo poblacional al que en cierto modo nos hemos referido en unas notas al libro Comunidad planeada, de Alomar, cobra cuerpo en algunos de tales preceptos, que casi nos harían ver la Ley del suelo como eventuales leyes de población o migracion. 
rrar en una palabra el amplísimo contenido de sus dos centenares largos de artículos, integrados muchos de ellos por párrafos varios y generalmente nada breves. ¿Es que el ordenamiento jurídico español, desgraciadamente tan ubérrimo en lo que a material legis- lativo se refiere, ha visto colmados sus depósitos con estos nuevos contingentes de normas? El que al quantum de nuestro Derecho administrativo se le adhieren nuevos materiales, no parece asustar tanto a nuestras autoridades, funcionarios y administrados, como el que pudiera derivarse de la calidad o carácter de los mismos.

Aquí la novedad se da en cierta medida, no tanto por el impacto. sociológico-jurídico, como por las zonas a que afecta. Con este solo dato podría justificarse que la nueva Ley es una disposición trascendental e importante. Trascendental, además, porque rebasa la órbita directa de su esfera de aplicación, pese a la serie de relaciones jurídicoprivadas y jurídico-públicas que comporta. Tịene o tendrá pues una vigencia directa e indirecta. Habrá una transustanciación de lo estrictamente urbanístico y jurídico-inmobiliario que sus normas reflejan. Porque, además, muchas de ellas insinúan, como decíamos, nuevás orientaciones o actuaciones en el derecho de propiedad, asimismo nuevas maneras de acción y organización administrativa.

Aun sin pensar en esos sutiles e inevitables desenvolvimientos, ios calificativos de trascendental e importante se ven en la función social de la propiedad que la Ley esboza. Creemos que ella tiene base bastante para aplicar aquellos apelativos. También la tiene los perfiles que se marcau para un posible desarrollo, desenvolvimiento o utilización de la iniciativa privada y de las aautonomías localess. Igualmente las alusiones a "gerencia urbanísticas como posibilidad optativa. Pero, sobre todo, es la recepción del planismo o planificación (conceptos atenuados en la terminología de la Ley por el eufemisma neológico del planeamiento), lo que en nuestro sentir da a la norma un mayor relieve político-administrativo, e incluso hasta podría verse en ello cierto matiz constitucional, porque tales principios planificadores, así como el dirigismo demográfico y geopolítico, para ser más expresivos, dirigismo poblacional (9), que allí se contiene y, en defini-

(9) Entendemos por tal no s6lo la política de contencion del desarrollo 
tiva, todas las proporciones o instrumentaciones del intervencionismo del Estado o entes locales, que de la teoría general de la Ley.o de su articulado se coligen, pudiera ofrecer nuevas perspectivas del derecho fundamental de alibre circulación o residencias.

No queremos con esto indicar que se pudieran producir fricciones con el artículo 14 del Fuero de los Españoles; no quisiéramos que esto pudiera tomarse por una posible imputación de inconstitucionalidad, por supuesta lesión a un principio, hasta ahora tradicionalmente respetado en las sucesivas declaraciones de derechos, así como en los códigos políticos hoy vigentes. No tratamos de hacer una crítica, ni siquiera una exégesis general, de los principios fundamentales de la Ley, sino tan sólo destacar algunos de los que juzgamos más relevantes o que mejor coadyuvan a realzar la trascendencia e importancia de aquélla.

Dentro de una consideración dinámica de la Ley del Suelo o efectividad de su normativa y de su programática, había que repetir, parodiando como en tantísimas otras disposiciones, la célebre frase napoleónica de que la Administración es esencialmente un aarte de ejecución. La lucha contra el suburbio, el esfuerzo por una mejora estética, técnica y social, del medio ambiente, donde se fijan las grandes o pequeñas agrupaciones humanas, no puede depender sólo de que se respete en términos absolutos aquel derecho fundamental, pero tampoco depende exclusivamente la mejora de nuestras casas, de nuestras ciudades y de nuestra organización urbana, de que exista un buen plan o una buena colección de planes; no basta que la mens legislatoris esté imbuída de buenas intenciones y que los preceptos sean más o menos perfectos.

En esta Ley, al igual que en otras, haría falta contar con el tacto, habilidad, entusiasmo, perspicacia, rectitud, buen sentido e inteligen-

de población en ciudades hipersaturadas, mediante la creación de poblados satélites, así como la colonización interior, con la consiguiente repoblación de zonas semideserticas, la posible atenuación del absentismo y thasta la probable estratificación sociológica por efecto de una rígida zonización (de la que hallariamos su prehistoria en la división funcional o profesional de ciertas calles en ciudades del medievo), sino que al hablar más genéricamente de dirigismo poblacional se piensa más que nada en una redistribución de la población, por medios más o menos indirectos. 
cia de los encargados de aplicarla. Si existen actitudes de incompren. sión, incluso por falta de suficiente agudez, o discernimiento en los miles de personas a quienes sus preceptos pueden afectar, es muy difícil que arraigue. Si su normativa no se acepta sinceramente como un bien o incluso como un mal menor, si se descubren resquicios por donde se abra paso el tristemente célebre ase acata pero no se cumplev, con toda su secuela de indiferencias, reservas mentales o resiijtencias pasivas, de poco servirá la Ley. Y su inutilidad no podrá atenuaria el correcto aparato coactivo, robustecido en este caso con sauciones indirectas en el jus disponendi de los propietarios y demás beneficiarios, que alcanza también a derechos de los concesionarios y asinismo a esa especie de jus disponendi de las facultades administrativas de los entes locales. Ni las gravosas multas, ni la movilización forzosa de solares, ni las exacciones con fịnes no fiscales, ni una seria y severa tutela de derechos y deberes de los Ayuntamientos 】 Diputaciones, así como de las Comisiones provinciales, Comisión central, etc. (10), podrán servir de mucho si no hay espíritu de acatamiento funcional. Para la eficacia de una Ley de la índole de la presente, no basta el simple hecho de su promulgación y su intensa publicidad (acompañada por una vacatio legis excepcional); su escueta difusión es insuficiente si no se preparan debidamente los ellcargados de aplicarla, se difunden sin recelo sus doctrinas (11), se

(10) Hasta el mismo Consejo Nacional, por su jerárquica dependencia del Ministro, entendemos que puede ser estimulado y sancionado políticamente. Este nuevo y alto órgano consultivo, aparte de su carácter asesor, es órgano coordinador, "rector y resolutorio" (Vid. párrafos 1 y 3 del art. 198). Parece, pues, que en él se corporeiza la máxima responsabilidad en la aplicación y eficacia de la Ley. Se dirá que la nueva Ley, además de aumentar el aparato burocrático del Estado con este importante y "superior" cuerpo consultivo, instaura cincuenta nuevas Comisiones provinciales (aunque en muchos casos sean refundiciones de otras). Quizá se aspire con dar cumplimiento a aquella regla, antibiológica, pero administrativamente correcta, de que el órgano crea la función o al menos especializa funciones de otros brganos. El impacto financiero del sostenimiento de estos nuevos servicios y el impacto político-jurídico, tanto en la libertad o propiedad de los vecinos, como en la autarquía de las Corporaciones, habrán de guardar discreto equilibrio para la más eficaz realización de la Ley.

(11) No sólo las de la Ley, según sintácticamente habría de entender- 
incita a las Corporaciones, a los dueños de terrenos, constructores de edificaciones $y$, en general, a todos, a una acción eficiente y a una demostración por hechos más que por pura propaganda de los posibles beneficios de su aplicación, así como al buen deseo de modificar aquello que sea menester $y$, sobre todo, a dar la sensación en los funcionarios (técnicos y autoridades incluídos) de que su actividad es siempre en pro del bien común, del interés público y bienestar general, que ofrecen en la nueva ordenación dimensiones múltiples.

\section{ESQUEMA Y PLAN}

La Ley se compone de 228 artículos, divididos en VII títulos, más las disposiciones finales y las transitorias. Ni la estructura de los títulos, ni la del articulado es totalmente homogénea (12), pese a la tendencia a la uniformidad. Los títulos se dividen en capítulos, subdivididos a su vez algunos en secciones; la mayoría de los artículos se subdividen en apartados numerados, algunos de los cuales a su vez comprenden varios párrafos ordenados por letras.

Por su contenido, vertebración y propósitos, es más que una Ley orgánica y llega casi a ser un verdadero cuerpo legal. Sin embargo, estrictamente y desde el punto de vista del déficit de refundición (además de anunciar un índice de vigencia de otras normas, se expresan algunas que quedan en vigor), no puede ser calificado de Código urbanístico. La Disposición transitoria $4 .^{\mathrm{a}}$, en su párafo 3 ,

se, sino también las opiniones de autores, funcionarios e incluso administrados.

(12) En los artículos encontramos algunos muy breves, como el primero (que tiene catorce palabras) y el 36 (con sólo doce), frente al tercero, que es el más largo de todos, con cinco apartados, divididos los cuatro primeros en varios párrafos, alguno de ellos extenso, como el $g$ ) del 1 , dedicado a zonas.

En la división en títulos no existe equivalencia, por ejemplo, entre el Tít. preliminar con cinco artículos y el I con 55. En cambio, los Títulos II y III tienen casi igual número de artículos (41 y 40 , respectivamente). El emplazamiento o sistematización de preceptos, así como la seriación de los respectivos capítulos, parece razonable. 
prevé otras leyes que pueden quedar parcialmente en vigor al ser adaptadas a ésta. Por otro lado, no cabe olvidarse de ciertos preceptos de la Ley de Régimen local junto con el nuevo Reglamento de Obras pendiente de dictarse $y_{2}$ sobre todo, la iniciativa normativa de los mismos órganos encargados de aplicar la Ley. Los propios Ayuntamientos, a través de sus Ordenanzas, seguirán creando derecho urbanístico, en sentido objetivo.

Mas si parece impropio el calificativo de Código urbanístico, más aún sería hablar de codificación inmobiliaria. Ni siquiera es la única aLey del Suelon; en efecto, se dió el contraste y oportuna circunstancia de que por las calendas que el Proyecto se presentaba a las Cortes y comenzaba a récibirse una gran parte de las múltiples enmiendas presentadas al mismo, se aprobaba en la Comisión de Agricultura el dictamen de otra Ley del Suelo (para la lucha contra la erosión, conservación y mejora de terrenos agrícolas), que fué promulgada el 20 de julio de 1955.

Eugenio Pérez Botija. 


\section{SISTEMA DE LA LEY}

El plan de la Ley es el siguiente:

\begin{tabular}{|c|c|}
\hline TITULO PRELIMINAR & $\begin{array}{l}\text { Finalidades } \\
\qquad y \\
\text { campos de aplicación }\end{array}$ \\
\hline $\begin{array}{c}\text { Titulo I } \\
\text { Planaakianto }\end{array}$ & $\begin{array}{l}\text { Clases de Planes } \\
\text { Formación } \\
\text { Efectos } \\
\text { Normas complementaries }\end{array}$ \\
\hline $\begin{array}{l}\text { TITULO Il } \\
\text { RÉGIMEN DEL SURLO }\end{array}$ & $\begin{array}{l}\text { Calificación } \\
\text { Patrimonio municipal } \\
\text { Parcelaciones } \\
\text { Valoraciones }\end{array}$ \\
\hline
\end{tabular}

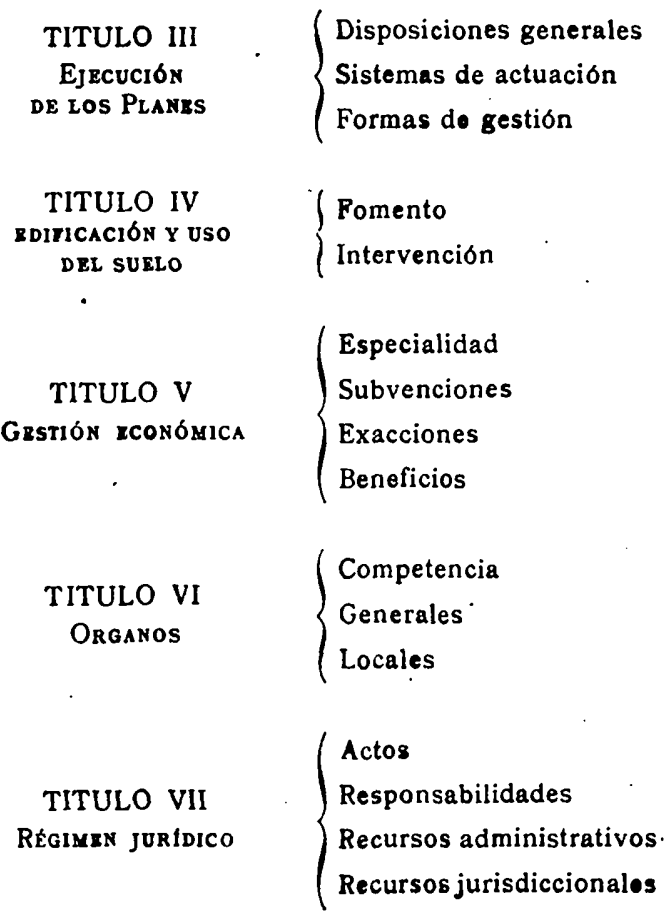


REVL-1956, núm. 88. PEREZ BOTIJA, EUGENIO. SINTESIS NORMATIVA DE LA LEY DEL SUELO. 